Article

\title{
Dietary Diversity and Nutritional Adequacy among an Older Spanish Population with Metabolic Syndrome in the PREDIMED-Plus Study: A Cross-Sectional Analysis
}

\author{
Naomi Cano-Ibáñez 1,2,3 (D), Alfredo Gea 4,5,6, Miguel A. Martínez-González 4,5,6,7 (D), \\ Jordi Salas-Salvadó 6,8,9,10 ${ }^{\mathbb{D}}$, Dolores Corella ${ }^{6,11}\left(\mathbb{D}\right.$, M. Dolors Zomeño ${ }^{12,13}$, Dora Romaguera ${ }^{6,14}$, \\ Jesús Vioque ${ }^{2,15} \mathbb{D}_{\text {, }}$, Fernando Aros ${ }^{6,16}$, Julia Wärnberg ${ }^{6,17}$ (D) J. Alfredo Martínez ${ }^{6,18,19}$ (D), \\ Lluis Serra-Majem ${ }^{6,20}\left(\mathbb{D}\right.$, Ramón Estruch ${ }^{6,21}$, Francisco J. Tinahones ${ }^{6,22}$, José Lapetra ${ }^{6,23}$, \\ Xavier Pintó ${ }^{6,24}$, Josep A. Tur ${ }^{6,25}$ (D), Antonio García-Ríos ${ }^{6,26}$, Blanca Riquelme-Gallego ${ }^{1}$, \\ Miguel Delgado-Rodríguez ${ }^{2,27}$, Pilar Matía ${ }^{6,28}$, Lidia Daimiel ${ }^{19}$ (D), Vicente Martín ${ }^{2,29}$ (D), \\ Josep Vidal ${ }^{30,31}$, Clotilde Vázquez ${ }^{6,32}$, Emilio Ros ${ }^{6,33}{ }^{(D)}$, Pilar Buil-Cosiales ${ }^{4,6,34}$ (D), \\ Andrés Díaz-López ${ }^{6,8,9,10}\left(\mathbb{D}\right.$, Rebeca Fernández-Carrión ${ }^{6,11}$, Montserrat Fitó ${ }^{6,12,13}$, \\ Jadwiga Konieczna 6,14, Leyre Notario-Barandiaran 2,15, Ángel M. Alonso-Gómez 6,16 ${ }^{\mathbb{D}}$, \\ Eugenio Contreras-Fernández ${ }^{35}$, Itziar Abete ${ }^{6,18} \mathbb{D}$, Almudena Sánchez-Villegas ${ }^{6,20}$, \\ Rosa Casas 6,21 (D), Araceli Muñoz-Garach 6,22, José Manuel Santos-Lozano 6,23,36, \\ Laura Gallardo-Alfaro ${ }^{25}$, Josep Basora ${ }^{6,8,9,10}$, Olga Portoles 6,11, Miguel Ángel Muñoz ${ }^{37}$, \\ Manuel Moñino 6,14, Salvador Miralles Gisbert 2,15 , Anai Moreno Rodríguez ${ }^{16}$, \\ Miguel Ruiz-Canela 4,5,6 (D), Antoni Palau Galindo 6,8,9,38, Karla Alejandra Pérez-Vega ${ }^{12}$ and \\ Aurora Bueno-Cavanillas 1,2,3,*(D)
}

1 Department of Preventive Medicine and Public Health, University of Granada, 18011 Granada, Spain; ncaiba@ugr.es (N.C.-I.); blanca.riquel@gmail.com (B.R.-G.)

2 CIBER Epidemiología y Salud Pública (CIBERESP). Instituto de Salud Carlos III (ISCIII), 28029 Madrid, Spain; vioque@umh.es (J.V.); mdelgado@ujaen.es (M.D.-R.); vicente.martin@unileon.es (V.M.); lnotario@umh.es (L.N.-B.); sjmirallesgis@gmail.com (S.M.G.)

3 Instituto de Investigación Biosanitaria de Granada (ibs.GRANADA), 18012 Granada, Spain

4 University of Navarre, Department of Preventive Medicine and Public Health, Medical School, 31008 Pamplona, Spain; ageas@unav.es (A.G.); mamartinez@unav.es (M.A.M.-G.); pilarbuilc@gmail.com (P.B.-C.); mcanela@unav.es (M.R.-C.)

5 Navarra institute for health research (IdisNa), 31008 Pamplona, Spain

6 CIBER Fisiopatología de la Obesidad y Nutrición (CIBEROBN), Instituto de Salud Carlos III (ISCIII), 28029 Madrid, Spain; jordi.salas@urv.cat (J.S.-S.); dolores.corella@uv.es (D.C.); doraromaguera@yahoo.es (D.R.); luisfernando.aros@ehu.eus (F.A.); jwarnberg@uma.es (J.W.); jalfmtz@unav.es (J.A.M.); lluis.serra@ulpgc.es (L.S.-M.); restruch@clinic.ub.es (R.E.); fjtinahones@hotmail.com (F.J.T.); jlapetra@ono.com (J.L.); xpinto@bellvitgehospital.cat (X.P.); pep.tur@uib.es (J.A.T.); angarios2004@yahoo.es (A.G.-R.); pilar.matia@gmail.com (P.M.); clotilde.vazquez@fjd.es (C.V.); eros@clinic.ub.es (E.R.); andres.diaz@urv.cat (A.D.-L.); rebeca.fernandez@uv.es (R.F.-C.); mfito@imim.es (M.F.); jadzia.konieczna@gmail.com (J.K.); angelmago13@gmail.com (Á.M.A.-G.); iabetego@unav.es (I.A.); almudena.sanchez@ulpgc.es (A.S.-V.); rcasas1@clinic.cat (R.C.); araceli.munoz.garach.sspa@juntadeandalucia.es (A.M.-G.); josemanuel.santos@ono.com (J.M.S.-L.); jbasora.tarte.ics@gencat.cat (J.B.); Olga.portoles@uv.es (O.P.); mmonyino@gmail.com (M.M.); apalau@grupsagessa.com (A.P.G.) Department of Nutrition, Harvard T.H. Chan School of Public Health, Boston, MA 02115, USA

8 Universitat Rovira i Virgili, Departament de Bioquímica i Biotecnologia, Unitat de Nutrició, 43002 Reus, Spain

Institut d'Investigació Sanitària Pere Virgili (IISPV), 43204 Reus, Spain

10 University Hospital of Sant Joan de Reus, Nutrition Unit, 43204 Reus, Spain

11 Department of Preventive Medicine, University of Valencia, 46010 Valencia, Spain 
12 Unit of Cardiovascular Risk and Nutrition, Institut Mar d’Investigacions Mèdiques (IMIM), 08003 Barcelona, Spain; mariadoloreszf@blanquerna.edu (M.D.Z.); kperez@imim.es (K.A.P.-V.)

13 Human Nutrition Unit, Blanquerna-Ramon Llull University, 08001 Barcelona, Spain

14 Health Research Institute of the Balearic Islands (IdISBa), 07120 Palma de Mallorca, Spain

15 Nutritional Epidemiology Unit, Miguel Hernández University, ISABIAL-FISABIO, 03202 Alicante, Spain

16 Department of Cardiology, OSI ARABA, University Hospital Araba, University of the Basque Country UPV/EHU, 48940 Vitoria-Gasteiz, Spain; anai.m.rodriguez@gmail.com

17 Department of Nursing, School of Health Sciences. University of Malaga- Instituto de Investigación Biomédica de Málaga (IBIMA), 29010 Málaga, Spain

18 Department of Nutrition, Food Sciences, and Physiology, Center for Nutrition Research, University of Navarra, 31008 Pamplona, Spain

19 Nutritional Genomics and Epigenomics Group, IMDEA Food, CEI UAM + CSIC, 28049 Madrid, Spain; lidia.daimiel@imdea.org

20 Research Institute of Biomedical and Health Sciences. University of Las Palmas de Gran Canaria, 35016 Las Palmas de Gran Canaria, Spain

21 Department of Internal Medicine, Institut d’Investigacion Biomèdiques August Pi Sunyer (IDIBAPS), Hospital Clinic, University of Barcelona, 08036 Barcelona, Spain

22 Virgen de la Victoria Hospital, Department of Endocrinology, Instituto de Investigación Biomédica de Málaga (IBIMA), University of Málaga, 29016 Málaga, Spain

23 Department of Family Medicine, Research Unit, Distrito Sanitario Atención Primaria Sevilla, 41013 Sevilla, Spain

24 Lipids and Vascular Risk Unit, Internal Medicine, Hospital Universitario de Bellvitge, Hospitalet de Llobregat, 08907 Barcelona, Spain

25 Research Group on Community Nutrition \& Oxidative Stress, University of Balearic Islands, 07122 Palma de Mallorca, Spain; laura.gallardo@uib.es

26 Lipids and Atherosclerosis Unit, Department of Internal Medicine, Maimonides Biomedical Research Institute of Córdoba (IMIBIC), Reina Sofía University Hospital, University of Córdoba, 14004 Córdoba, Spain

27 Department of Health Sciences, University of Jaen, 23071 Jaen, Spain

28 Department of Endocrinology and Nutrition, Instituto de Investigación Sanitaria Hospital Clínico San Carlos (IdISSC), 28040 Madrid, Spain

29 Institute of Biomedicine (IBIOMED), University of León, 24071 León, Spain

30 Department of Endocrinology, Institut d’ Investigacions Biomédiques August Pi Sunyer (IDIBAPS), Hospital Clinic, University of Barcelona, 08036 Barcelona, Spain; jovidal@clinic.cat

31 CIBER Diabetes y enfermedades metabólicas (CIBERDEM), ISCIII, 28029 Madrid, Spain

32 Department of Endocrinology, Fundación Jiménez-Díaz, 28040 Madrid, Spain

33 Lipid Clinic, Department of Endocrinology and Nutrition, IDIBAPS, Hospital Clinic, 08036 Barcelona, Spain

34 Primary Care, Health Service of Navarra-Osasunbidea, 31002 Pamplona, Spain

35 Unidad Gestión Clínica de Prevención, Promoción y Vigilancia de la Salud, Distrito Atención Primaria Costa del Sol, Servicio Andaluz de Salud. Red de Investigación Servicios De Salud en Enfermedades

Crónicas (REDISSEC), 29651 Málaga, Spain; eugenio.contreras.sspa@juntadeandalucia.es

36 Department of Medicine. University of Sevilla, 41004 Sevilla, Spain

37 Primary Care Division of Barcelona, Institut Català de la Salud-IDIAP Jordi Gol, 08007 Barcelona, Spain; mamunoz.bcn.ics@gencat.cat

38 ABS Reus V. Centre d'Assistència Primària Marià Fortuny, SAGESSA, 43203 Reus, Spain

* Correspondence: abueno@ugr.es; Tel.:+34-958-24-66-58

Received: 16 March 2019; Accepted: 24 April 2019; Published: 26 April 2019

Abstract: Dietary guidelines emphasize the importance of a varied diet to provide an adequate nutrient intake. However, an older age is often associated with consumption of monotonous diets that can be nutritionally inadequate, increasing the risk for the development or progression of diet-related chronic diseases, such as metabolic syndrome (MetS). To assess the association between dietary diversity (DD) and nutrient intake adequacy and to identify demographic variables associated with DD, we cross-sectionally analyzed baseline data from the PREDIMED-Plus trial: 6587 Spanish adults aged 55-75 years, with overweight/obesity who also had MetS. An energy-adjusted dietary diversity 
score (DDS) was calculated using a 143-item validated semi-quantitative food frequency questionnaire (FFQ). Nutrient inadequacy was defined as an intake below $2 / 3$ of the dietary reference intake (DRI) forat least four of 17 nutrients proposed by the Institute of Medicine (IOM). Logistic regression models were used to evaluate the association between DDS and the risk of nutritionally inadequate intakes. In the higher DDS quartile there were more women and less current smokers. Compared with subjects in the highest DDS quartile, those in the lowest DDS quartile had a higher risk of inadequate nutrient intake: odds ratio $(\mathrm{OR})=28.56$ (95\% confidence interval $(\mathrm{CI})$ 20.80-39.21). When we estimated food varietyfor each of the food groups, participants in the lowest quartile had a higher risk of inadequate nutrient intake for the groups of vegetables, OR $=14.03$ (95\% CI 10.55-18.65), fruits OR $=11.62(95 \%$ CI 6.81-19.81), dairy products OR $=6.54(95 \%$ CI 4.64-9.22) and protein foods OR $=6.60(95 \%$ CI 1.96-22.24). As DDS decreased, the risk of inadequate nutrients intake rose. Given the impact of nutrient intake adequacy on the prevention of non-communicable diseases, health policies should focus on the promotion of a healthy varied diet, specifically promoting the intake of vegetables and fruit among population groups with lower DDS such as men, smokers or widow(er)s.

Keywords: dietary diversity; nutrient adequacy; metabolic syndrome; aging; PREDIMED-Plus study

\section{Introduction}

Metabolic syndrome (MetS), a clustering of risk factors (central obesity, insulin resistance, dyslipidemia and hypertension) [1], is a well-known condition in the causal pathway of cardiovascular disease (CVD). MetS has also been associated with a higher risk of other chronic diseases, such as cancer [2] and neurodegenerative diseases [3]. In recent years, the prevalence of MetS has increased worldwide to the point that presently it is considered as a major public health problem [4]. This trend has also been observed in Spain, where the current prevalence of MetS is approximately 22.7\% and increases with age [5]. Typically subjects with MetS have a higher use of health care services, incrementing costs [6].

MetS is a multifactorial disease that may be associated with some modifiable risk behaviors, such as unhealthy lifestyles and dietary patterns [7]. Among these factors, dietary intake plays a critical role in the prevention and treatment of MetS. Thus, dietary patterns that include healthy varied food groups and which provide adequate nutrient intake have been shown to be beneficial in the progression of MetS [8]. In this sense, the Mediterranean dietary pattern (MedDiet) has been related, not only to a delay in the progression and a lower mortality of MetS [9], but also to an adequate nutritional intake [10]. This can be explained by the great variety of food products that characterize the MedDiet. These foods, such as fruit and vegetables, nuts, legumes, fish and whole grain cereals, have a relatively low caloric value but a high nutrient content, increasing the probability to meet nutritional requirements [11].

Spanish dietary guidelines have emphasized the importance of a varied, balanced and moderated diet to reduce the risk of diet-related chronic diseases [12]. However, the role of a varied diet on chronic disease development is still uncertain. Some studies have suggested that dietary diversity (DD) contributes to high energy consumption and has a positive association with a poor quality diet, increasing the risk of MetS in older adults [13-16]; other researchers have reported that DD is a key component of high-quality diets, being associated with nutrient adequacy [17] and reducing the rates of CVD [18] and MetS [19] in the overall population.

Older adult populations with chronic diseases are considered vulnerable groups, as they are at greater nutritional risk due to a higher prevalence of inadequate nutrient intakes [20]. This could be a consequence of the consumption of monotonous and nutritionally inadequate diets, influenced by several factors, including loneliness, low socioeconomic status and functional quality [21]. 
There is evidence that nutritional inadequacy is prevalent in the older Spanish population [22], likely related to a monotonous diet and which could accelerate the progression of chronic diseases such as MetS. In this study we examined DD among PREDIMED-Plus participants, an older adult population with MetS, with the aim of assessing the association between DD and nutrient adequacy and to identify demographic variables associated with DD.

\section{Materials and Methods}

\subsection{Design of the Study}

A cross-sectional analysis on baseline data of the PREDIMED-Plus study was conducted. The PREDIMED-Plus study is an ongoing multicenter, randomized and parallel-group primary cardiovascular prevention trial. The PREDIMED-Plus study aims to assess the potential advantages of the synergy of a high-quality energy reduced MedDiet plus a weight-loss intervention and behavioral support on the incidence of CVD, in comparison to standard MedDiet advice (control group). The participant recruitment methods and data collection process have been described previously [23]. The Institutional Review Boards of all participating centers approved the study protocol. The clinical trial was registered in 2014 at the International Standard Randomized Controlled Trial (www.isrctn.com/ISRCTN89898870). All participants provided written informed consent.

\subsection{Study Population}

The study participants were men and women (55-75 years old and 60-75 years old, respectively), with overweight or obesity (body mass index (BMI) $\geq 27$ and $\leq 40 \mathrm{~kg} / \mathrm{m}^{2}$ ), who at baseline met at least three of the MetS criteria. The MetS criteria used have been previously described [24].

A total of 6874 subjects were recruited and randomized in 23 centers of the PREDIMED-Plus clinical trial from October 2013 to December 2016, from different universities, hospitals and research institutes across Spain. Of these, 287 participants were excluded for the present study (Figure 1): 47 participants because they did not complete the food frequency questionnaire (FFQ), and 240 participants because they reported values for total energy intake outside predefined limits $(<3347 \mathrm{~kJ}$ $<800 \mathrm{kcal} /$ day or $>17,573 \mathrm{~kJ}>4000 \mathrm{kcal} /$ day for men); $(<2510 \mathrm{~kJ}<500 \mathrm{kcal} /$ day or $>14,644 \mathrm{~kJ}>3500$ $\mathrm{kcal} /$ /day for women) [25]. A final sample of 6587 participants was analyzed.

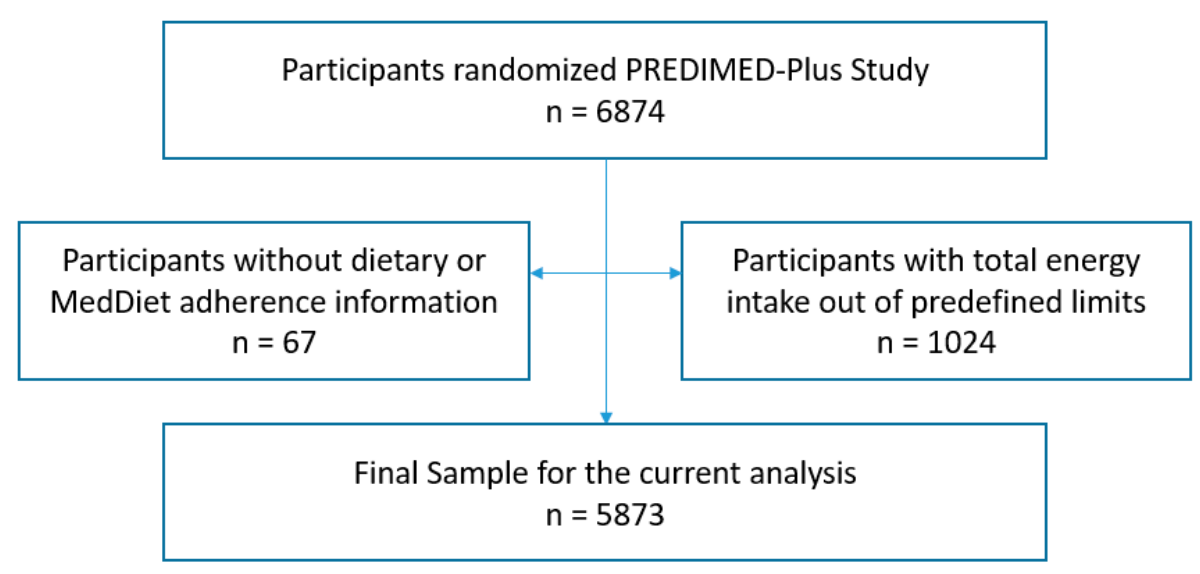

Figure 1. Flow-chart of participants.

\subsection{Dietary Intake Assessment}

Trained dieticians collected data on dietary intake at baseline in a face-to-face interview. Dietary intake was assessed using a 143 item semi-quantitative FFQ previously and repeatedly validated in Spain [26]. The FFQ provides a list of foods commonly used by the Spanish population and asks about the consumption of these foods during the previous year. It includes nine response options (never 
or almost never, 1-3 times a month, once a week, 2-4 times a week, 5-6 times a week, once a day, 2-3 times a week day, 4-6 times a day and more than 6 times a day). The indicated frequencies of consumption were converted to intakes per day and multiplied by the weight of the standard serving size in order to estimate the intake in grams per day. Nutrient information was derived from Spanish food composition tables $[27,28]$.

\subsection{Dietary Diversity Score Construction}

Using the 143-item validated FFQ mentioned above, we calculated an energy-adjusted DD score (DDS). This DDS was calculated by the method originally developed by Kant et al. [29] and recently used by Farhangi et al. [30]. We included five food groups: Vegetables, fruits, cereals, dairy products and protein food groups (legumes, meat, fish, eggs and nuts), based on the food groups recommended by the Spanish guidelines' pyramid [12]. The vegetable group was divided into four subgroups, including: Green vegetables, tomatoes, yellow vegetables and mushrooms. The cereal group included potatoes and refined or whole grain cereals (bread, pasta, rice and breakfast cereals). The fruit group included all fresh fruit products divided in three categories: Citrus fruits, tropical fruits and other seasonal fruits. The dairy group included all kinds of milk, yogurt and cheese. Protein food groups included legumes (peas, beans, lentils and chickpeas), white meats (poultry and rabbit), fish (oily fish, white fish and other shellfish/seafood), eggs and nuts. Non-recommended food groups (that should be consumed as little as possible) [27], including sugar food groups (pastries, pies, biscuits, chocolate, fruit in sugar syrup and fruit juices) and food groups with high salt and/or saturated fats (butter, margarine, unhealthy vegetable fats, red meat, processed meats, sauces, pre-cooked dishes, condiments and snacks) were not included in the analysis as they are less healthy products and their variety is not desirable. These groups were used to define food variety groups. Therefore, we only analyzed diversity of recommended food groups, because the more important question was the percentage of total energy supplied by these food groups and our analyses were adjusted for total energy intake.

To be counted as a consumer for any of the food group categories reported previously, a subject should consume at least half of the recommended serving during one day (for example, if the Spanish nutritional recommendation advises a usual protein intake of three servings per week, for each protein item, participants should consume at least 1.5/7 servings/day). Within each food group, we summed up the number of items consumed. Each of the five predefined food categories received a maximum diversity score of 2 points, therefore the sum was rescaled to a 0-to- 2 score by multiplying the score by 2 and dividing by the maximum score in that food group. Total DDS is the sum of the scores of the five main groups, theoretically ranging between 0 and 10 points. The score was adjusted for total energy intake, due to the general concern that high food variety might be a consequence of overconsumption of energy [14]. Finally, DDS was categorized in quartiles (Q) and the cutoff points were 3.8, 4.6 and 5.4. The variety in each food group was classified into four categories $(C)$ : $C 1=0$ points, $C 2 \geq 0-\leq 0.5$ points, C $3 \geq 0.5-<1$ points and $C 4 \geq 1$ point.

Subjects were asked about MedDiet adherence using a 17-item screening questionnaire used to both evaluate compliance with the intervention and guide the motivational interviews during the study follow-up. This screener is a modification of a previously validated 14-item MedDiet adherence questionnaire [31]. Compliance with each of the 17 items relating to characteristic food habits was scored with 1 point, and 0 points otherwise, so that the total score range was $0-17$, with 0 meaning no adherence and 17 meaning maximum adherence. Adherence to the MedDiet, was categorized in tertiles as lower level (1st tertile, $\leq 7$ points), medium (2nd tertile, 8-10 points) or higher level of adherence (3rd tertile, $\geq 11$ points).

\subsection{Nutrient Adequate Intake}

The dietary intake of 17 selected nutrients, including vitamins $A, B_{1}, B_{6}, B_{9}, B_{12}, C, D, E$, minerals such as calcium, phosphorus, magnesium, iron, iodine, potassium, selenium and zinc and dietary fiber, was compared with age and sex-specific recommended intakes for these nutrients according to the 
established dietary reference intake (DRI) recommendations for the North-American population [32]. DRI is the general term for a set of reference values used to plan and assess nutrient intakes for healthy people. These values vary by age and sex. Intake levels above DRI imply a low likelihood of inadequate intake. To decrease potential measurement errors derived from the use of the FFQ, we calculated the proportion of individuals with intakes below two thirds (2/3) of the DRIs [33]. Furthermore, we estimated the proportion of inadequate intake according to European Food Safety Agency (EFSA) average requirements (ARs), taking as reference adequate intake (AI) when ARs were not available [34]. Results were based on dietary intake data only, excluding supplements.

\subsection{Assessment of Non-Dietary Variables}

At the baseline visit, trained PREDIMED-Plus staff collected information on lifestyle variables, educational achievement and socioeconomic status. The variables collected were sex, age (55-70 years and $>70$ years), educational level (primary, secondary and tertiary level, which includes university studies), civil status (married, widowed, divorced/single or other, which includes single participants and those who are priests or nuns who were categorized as "religious") and whether they lived alone or not. Other lifestyle variables such as smoking habit (non-smoker, current smoker or never smoker), alcohol intake (measured as a continuous variable and expressed as intake in g/day) and physical activity (less active, moderately active and active) were taken into account. Individuals were classified based on their level of physical activity using a validated Spanish version of the Minnesota questionnaire: Less active ( $<4$ MET), moderately active (4-5.5 MET) and active $(\geq 6$ MET) physical activity level $[35,36]$. Anthropometric variables (weight, height and waist circumference) were determined by trained staff in accordance with the PREDIMED-Plus operations protocol. Weight and height were measured with calibrated scales and a wall-mounted stadiometer, respectively. BMI was calculated as the weight in kilograms divided by the height in meters squared. Waist circumference (WC) was measured midway between the lowest rib and the iliac crest using an anthropometric tape.

\subsection{Statistical Analysis}

Data were analyzed using Stata (12.0, StataCorp LP, College Station, TX, USA). We used the PREDIMED-Plus baseline database generated in August 2017. Participants were classified according to DDS quartiles. Baseline characteristics of participants were described as means \pm standard deviations (SD) for continuous variables or number and percentages for categorical variables. Comparison of quantitative variables across DDS quartiles was performed using ANOVA. Pearson $\chi^{2}$ test was used to compare the distribution of qualitative variables among DDS quartiles. A linear regression model was fitted to estimate the association of sociodemographic and lifestyle variables (sex, age, educational level, civil status, living alone, physical activity, smoking and drinking status) with DDS. Logistic regression models were used to evaluate the association between nutritional inadequate intakes $(\geq 4$ nutrients) as dependent variable and total DDS or food variety groups as the main independent variables. All analyses were adjusted for potential confounders based on prior knowledge: Sex, age, energy intake, BMI, WC, level of education, smoking status, physical activity, MedDiet adherence, marital status and living alone. We used a significance level of 0.05 for all analyses.

\section{Results}

\subsection{Baseline Characteristics of PREDIMED-Plus Participants by Quartiles of DDS}

Table 1 shows the comparison of demographic, anthropometric and lifestyle variables according to quartiles of DDS. We found significant differences for age, sex, smoking habits, marital status, educational level and WC $(p<0.001)$, but not for physical activity or BMI. Participants in the top DDS quartile (Q4) were older (65.8 \pm 4.7$)$ and more likely to be women $(63.6 \%)$, never smokers $(54.3 \%)$ and married $(77.8 \%, p<0.05)$ in comparison with the lower DDS quartiles. Moreover, participants in the top DDS quartile had a lower WC $(106.3 \pm 9.6)$ and lower educational level. However the magnitude 
of the differences across quartiles was small and should be interpreted in the light of the large power and sample size of the study.

Table 1. Baseline characteristics of PREDIMED-Plus participants by quartiles of an energy-adjusted dietary diversity score (DDS, total population $=6587$ ).

\begin{tabular}{|c|c|c|c|c|c|}
\hline & $\begin{array}{c}\text { Q1 } \\
(n=1647)\end{array}$ & $\begin{array}{c}\mathrm{Q} 2 \\
(n=1647)\end{array}$ & $\begin{array}{c}\text { Q3 } \\
(n=1647)\end{array}$ & $\begin{array}{c}\mathrm{Q} 4 \\
(n=1646)\end{array}$ & $\begin{array}{c}p \\
\text { Value }\end{array}$ \\
\hline \multicolumn{6}{|c|}{ Age (Year), $n(\%)$} \\
\hline $55-70$ years & $1442(87.6)$ & $1416(86.0)$ & $1403(85.2)$ & $1356(82.4)$ & \multirow{2}{*}{$<0.001$} \\
\hline$>70$ years & $205(12.5)$ & $231(14.0)$ & $244(14.8)$ & $290(17.6)$ & \\
\hline Mean \pm SD & $64.1 \pm 5.1$ & $64.8 \pm 4.9$ & $65.3 \pm 4.8$ & $65.8 \pm 4.7$ & $<0.001$ \\
\hline \multicolumn{6}{|c|}{ Sex, $n(\%)$} \\
\hline Male & $1116(67.8)$ & $916(55.6)$ & $770(46.8)$ & $600(36.5)$ & \multirow{2}{*}{$<0.001$} \\
\hline Female & $531(32.2)$ & $731(44.4)$ & $877(53.3)$ & $1046(63.6)$ & \\
\hline \multicolumn{6}{|c|}{ Smoking Habits, $n$ (\%) } \\
\hline Current Smoker & $297(18.0)$ & $195(11.8)$ & $171(10.4)$ & $152(9.2)$ & \multirow{4}{*}{$<0.001$} \\
\hline Former Smoker & $793(48.2)$ & $747(45.4)$ & $722(43.8)$ & $593(36.0)$ & \\
\hline Never Smoker & $548(33.3)$ & $699(42.4)$ & 749 (45.5) & $893(54.3)$ & \\
\hline Without information & $9(0.6)$ & $6(0.4)$ & $5(0.3)$ & $8(0.5)$ & \\
\hline \multicolumn{6}{|c|}{ Physical Activity, $n(\%)$} \\
\hline Less active & $1014(61.7)$ & $985(59.9)$ & $983(59.9)$ & $940(57.4)$ & \multirow{3}{*}{0.29} \\
\hline Moderately active & $294(17.9)$ & $304(18.5)$ & $319(19.4)$ & $326(19.9)$ & \\
\hline Active & $335(20.4)$ & $355(21.6)$ & $340(20.7)$ & $373(22.8)$ & \\
\hline \multicolumn{6}{|c|}{ Educational Level, $\boldsymbol{n}(\%)$} \\
\hline Tertiary level & $421(25.6)$ & $360(21.9)$ & $340(20.6)$ & $320(19.5)$ & \multirow{4}{*}{$<0.001$} \\
\hline Secondary level & $534(32.4)$ & $480(29.2)$ & $449(27.3)$ & $435(26.4)$ & \\
\hline Primary level & $679(41.3)$ & $796(48.4)$ & $842(51.1)$ & $873(53.1)$ & \\
\hline Without information & $13(0.7)$ & $11(0.6)$ & $16(1.0)$ & $18(1.0)$ & \\
\hline \multicolumn{6}{|c|}{ Civil Status, $n(\%)$} \\
\hline Married & $1258(76.7)$ & $1254(76.4)$ & $1243(75.7)$ & $1278(77.8)$ & \multirow{4}{*}{0.030} \\
\hline Widowed & $151(9.2)$ & $162(9.9)$ & $182(11.1)$ & $186(11.3)$ & \\
\hline Divorced/Separated & $145(8.8)$ & $123(7.5)$ & $130(7.9)$ & $117(7.1)$ & \\
\hline Others $^{a}$ & $93(5.2)$ & $108(6.2)$ & $92(5.3)$ & $65(3.8)$ & \\
\hline Living alone, $\mathrm{n}(\%)$ & $193(11.8)$ & $189(11.5)$ & $220(13.4)$ & $212(12.9)$ & 0.29 \\
\hline $\mathrm{BMI}\left(\mathrm{kg} / \mathrm{m}^{2}\right)$, Mean $\pm \mathrm{SD}$ & $32.6 \pm 3.4$ & $32.5 \pm 3.4$ & $32.5 \pm 3.5$ & $32.5 \pm 3.5$ & 0.82 \\
\hline WC (cm), Mean \pm SD & $109.3 \pm 9.5$ & $108.1 \pm 9.5$ & $107.0 \pm 9.7$ & $106.3 \pm 9.6$ & $<0.001$ \\
\hline
\end{tabular}

\subsection{Associations Between Demographic and Lifestyle Variables with DDS}

The associations between these demographic and lifestyle variables with DDS as a continuous variable are presented in Table 2. We observed that DDS was significantly higher among women (mean difference $=0.26,95 \%$ CI 0.18, 0.33), non-smokers (mean differences $=0.18,95 \%$ CI $0.09,0.27$ ) and participants with higher adherence to the MedDiet (mean difference $=0.65,95 \% \mathrm{CI} 0.58,0.73$ ), whereas alcohol intake (mean difference $=-0.01,95 \% \mathrm{CI}-0.01,-0.01$ ) and being widowed (mean difference $=-0.15,95 \% \mathrm{CI}-0.26,-0.05)$ were inversely associated with higher DDS. 
Table 2. Linear regression model to evaluate demographic and lifestyle variables associated with DDS (DDS measure as continuous variable).

\begin{tabular}{|c|c|c|}
\hline & \multicolumn{2}{|l|}{ Total DDS } \\
\hline & $\begin{array}{c}\text { Mean Differences } \\
(95 \% \mathrm{CI})\end{array}$ & $\begin{array}{c}p \\
\text { Value }\end{array}$ \\
\hline \multicolumn{3}{|c|}{ Sex } \\
\hline Men & 0 (ref) & \\
\hline Women & $0.26(0.18,0.33)$ & $<0.001$ \\
\hline \multicolumn{3}{|c|}{ Age } \\
\hline$\leq 70$ years & 0 (ref) & \\
\hline More 70 years & $0.06(-0.15,0.14)$ & 0.12 \\
\hline \multicolumn{3}{|c|}{ Smoking Habits } \\
\hline Current smoker & 0 (ref) & \\
\hline Former smoker & $0.14(0.06,0.23)$ & 0.001 \\
\hline Never smoker & $0.18(0.09,0.27)$ & $<0.001$ \\
\hline \multicolumn{3}{|c|}{ Physical Activity Status } \\
\hline Less active & 0 (ref) & \\
\hline Moderate active & $0.06(-0.01,0.13)$ & 0.11 \\
\hline Active & $0.03(-0.04,0.10)$ & 0.34 \\
\hline \multicolumn{3}{|c|}{ Educational Status } \\
\hline Tertiary Level & 0 (ref) & \\
\hline Secondary Level & $0.02(-0.05,0.09)$ & 0.59 \\
\hline Primary Le & $0.07(0.03,0.14)$ & 0.041 \\
\hline \multicolumn{3}{|c|}{ MedDiet Adherence } \\
\hline Low Adherence & 0 (ref) & \\
\hline Medium Adherence & $0.34(0.28,0.40)$ & $<0.001$ \\
\hline High Adherence & $0.65(0.58,0.73)$ & $<0.001$ \\
\hline \multicolumn{3}{|c|}{ Civil Status } \\
\hline Married & $0($ ref $)$ & \\
\hline Widowed & $-0.15(-0.26,-0.05)$ & 0.004 \\
\hline Divorced/Separated & $-0.12(-0.23,-0.02)$ & 0.026 \\
\hline Others $^{\mathrm{a}}$ & $-0.21(-0.34,-0.08)$ & 0.002 \\
\hline Living alone & $-0.31(-0.14,0.07)$ & 0.57 \\
\hline $\mathrm{WC}(\mathrm{cm})^{\mathrm{b}}$ & $-0.01(-0.01,0.01)$ & 0.57 \\
\hline BMI $\left(\mathrm{kg} / \mathrm{m}^{2}\right)^{\mathrm{b}}$ & $-0.01(-0.01,0.01)$ & 0.75 \\
\hline Alcohol intake $(\mathrm{g})^{\mathrm{b}}$ & $-0.01(-0.02,-0.01)$ & $<0.001$ \\
\hline
\end{tabular}

Linear regression model $(95 \% \mathrm{CI})$ for the DDS as a dependent variable according to baseline characteristics of participants. ${ }^{a}$ Others: Includes religious and single status. ${ }^{\mathrm{b}}$ 1-unit increase. Abbreviations: BMI, body mass index; $\mathrm{CI}$, confidence interval; DDS, dietary diversity score; SD, standard deviation; WC, waist circumference.

\subsection{Adherence to MedDiet and Dietary Intake of PREDIMED-Plus Participants by Quartiles of DDS Adjusted by Energy}

Comparing across DDS quartiles, individuals in Q4 had significantly higher MedDiet adherence, higher intake of dietary fiber, carbohydrates, proteins and polyunsaturated fat, but lower saturated fat intake (Table 3). Vitamin and mineral intake increased progressively across DDS quartiles $(p<0.001)$. However the magnitude of these differences across quartiles is small and should be interpreted in the light of the large power and sample size of the study. On the other hand, participants in the bottom DDS quartile (Q1) reported higher alcohol intake. Total energy intake followed a U-shaped line, higher in Q1 and Q4 than in Q2-Q3. Supplementary Table 1 (Table S1) shows the proportion of participants with an intake below $2 / 3$ of DRIs by DDS quartiles and is stratified by sex and group of age. The prevalence of inadequate intake of all nutrients decreased across DDS quartiles in all age and sex strata, except for vitamin D in older individuals. Vitamins B1, B12, C, phosphorus, iron, potassium, selenium and zinc presented high number of categories with zero cases, as nearly all the prevalent 
cases of deficient intake were at Q1 of DDS (Table S2.). These results were similar when the EFSA recommendations were used instead (Table S3.).

Table 3. Adherence to MedDiet, mean energy, alcohol and nutrient intakes of PREDIMED-Plus participants by quartiles of DDS adjusted by energy.

\begin{tabular}{|c|c|c|c|c|c|}
\hline & $\begin{array}{c}\text { Q1 } \\
(n=1647)\end{array}$ & $\begin{array}{c}\mathrm{Q} 2 \\
(n=1647)\end{array}$ & $\begin{array}{c}\mathrm{Q} 3 \\
(n=1647)\end{array}$ & $\begin{array}{c}\mathrm{Q} 4 \\
(n=1646)\end{array}$ & $\begin{array}{c}p \\
\text { Value }\end{array}$ \\
\hline \multicolumn{6}{|c|}{ MedDiet Adherence, $n(\%)$} \\
\hline Low adherence & $857(52.0)$ & $638(38.7)$ & $507(30.8)$ & $372(22.6)$ & \\
\hline Medium adherence & $602(36.7)$ & $686(41.7)$ & $717(43.5)$ & $684(41.6)$ & $<0.001$ \\
\hline High adherence & $188(11.4)$ & $323(19.6)$ & $423(25.7)$ & $590(35.8)$ & \\
\hline Mean \pm SD & $7.4 \pm 2.5$ & $8.3 \pm 2.6$ & $8.8 \pm 2.5$ & $9.5 \pm 2.6$ & $<0.001$ \\
\hline \multicolumn{6}{|c|}{ Nutrient Intake, Mean \pm SD } \\
\hline Total energy (Kcal/day) & $2382.3 \pm 612.8$ & $2345.0 \pm 557.9$ & $2340.7 \pm 527.0$ & $2397.1 \pm 502.6$ & 0.006 \\
\hline Total fat intake $(\%)$ & $39.9 \pm 7.1$ & $39.9 \pm 6.6$ & $39.5 \pm 6.3$ & $38.9 \pm 5.9$ & $<0.001$ \\
\hline Monounsaturated fat (\%) & $20.7 \pm 4.9$ & $20.8 \pm 4.7$ & $20.5 \pm 4.6$ & $20.1 \pm 4.3$ & 0.002 \\
\hline Polyunsaturated fat (\%) & $6.2 \pm 1.9$ & $6.3 \pm 1.9$ & $6.4 \pm 1.8$ & $6.6 \pm 1.8$ & $<0.001$ \\
\hline Saturated fat $(\%)$ & $10.1 \pm 2.2$ & $10.1 \pm 2.1$ & $9.9 \pm 1.9$ & $9.7 \pm 1.8$ & $<0.001$ \\
\hline Carbohydrate intake (\%) & $40.1 \pm 7.5$ & $40.2 \pm 7.0$ & $40.7 \pm 6.5$ & $41.3 \pm 6.1$ & $<0.001$ \\
\hline Protein intake $(\%)$ & $15.4 \pm 2.6$ & $16.6 \pm 2.7$ & $17.2 \pm 2.8$ & $17.9 \pm 2.6$ & $<0.001$ \\
\hline Fiber intake (g/day) & $21.4 \pm 7.8$ & $24.8 \pm 7.7$ & $27.1 \pm 7.8$ & $31.3 \pm 8.8$ & $<0.001$ \\
\hline Vitamin A ( $\mu \mathrm{g} /$ day) & $909.3 \pm 624.6$ & $1075.1 \pm 648.9$ & $1133.2 \pm 587.7$ & $1302.9 \pm 650.3$ & $<0.001$ \\
\hline Vitamin B1 (mg/day) & $1.5 \pm 0.4$ & $1.6 \pm 0.4$ & $1.7 \pm 0.4$ & $1.8 \pm 0.4$ & $<0.001$ \\
\hline Vitamin B6 (mg/day) & $2.0 \pm 0.5$ & $2.2 \pm 0.5$ & $2.4 \pm 0.5$ & $2.7 \pm 0.6$ & $<0.001$ \\
\hline Vitamin B9 ( $\mu \mathrm{g} /$ day $)$ & $290.7 \pm 82.3$ & $335.6 \pm 88.9$ & $363.6 \pm 90.9$ & $416.1 \pm 102.0$ & $<0.001$ \\
\hline Vitamin B12 ( $\mu \mathrm{g} /$ day $)$ & $9.0 \pm 4.5$ & $9.7 \pm 4.5$ & $10.1 \pm 4.3$ & $10.9 \pm 4.5$ & $<0.001$ \\
\hline Vitamin C (mg/day) & $147.5 \pm 66.4$ & $189.0 \pm 74.3$ & $216.5 \pm 78.3$ & $255.7 \pm 83.2$ & $<0.001$ \\
\hline Vitamin D ( $\mu \mathrm{g} /$ day $)$ & $5.3 \pm 3.2$ & $5.9 \pm 3.3$ & $6.4 \pm 3.4$ & $7.1 \pm 3.6$ & $<0.001$ \\
\hline Vitamin E (mg/day) & $9.6 \pm 4.1$ & $10.4 \pm 3.9$ & $10.7 \pm 3.7$ & $11.7 \pm 3.8$ & $<0.001$ \\
\hline Calcium (mg/day) & $876.6 \pm 325.3$ & $987.2 \pm 325.1$ & $1071.8 \pm 320.3$ & $1201.5 \pm 326.2$ & $<0.001$ \\
\hline Phosphorus (mg/day) & $1556.4 \pm 389.7$ & $1699.4 \pm 388.3$ & $1796.7 \pm 389.7$ & $1985.6 \pm 397.1$ & $<0.001$ \\
\hline Magnesium (mg/day) & $371.0 \pm 99.3$ & $403.7 \pm 98.4$ & $428.2 \pm 98.8$ & $479.4 \pm 108.5$ & $<0.001$ \\
\hline Iron (mg/day) & $15.2 \pm 3.9$ & $16.0 \pm 3.8$ & $16.6 \pm 3.7$ & $18.1 \pm 3.9$ & $<0.001$ \\
\hline Iodine ( $\mu \mathrm{g} /$ day $)$ & $242.9 \pm 163.6$ & $274.7 \pm 153.1$ & $297.0 \pm 155.3$ & $327.2 \pm 151.1$ & $<0.001$ \\
\hline Potassium (mg/day) & $3767.9 \pm 858.1$ & $4262.1 \pm 880.0$ & $4619.6 \pm 929.3$ & $5256.5 \pm 1053.4$ & $<0.001$ \\
\hline Selenium ( $\mu \mathrm{g} /$ day) & $113.6 \pm 36.8$ & $115.9 \pm 32.9$ & $116.4 \pm 31.3$ & $122.5 \pm 30.9$ & $<0.001$ \\
\hline Zinc (mg/day) & $12.5 \pm 3.5$ & $13.0 \pm 3.2$ & $13.2 \pm 3.1$ & $14.1 \pm 3.1$ & $<0.001$ \\
\hline Alcohol intake (g/day), Mean \pm SD & $16.5 \pm 19.4$ & $11.7 \pm 15.0$ & $9.1 \pm 12.4$ & $6.8 \pm 9.8$ & $<0.001$ \\
\hline
\end{tabular}

Values are presented as means \pm SD for continuous variables and $n(\%)$ for categorical variables. Pearson's chi-square test was performed for categorical variables and ANOVA test for continuous variables. Abbreviations: DDS, dietary diversity score; $Q$, quartile; SD, standard deviation.

3.4. Distribution of Participants ny Number of Nutrients below Adequate Intake According to the DDS by Age and Sex

Table 4 shows the prevalence of four or more inadequacies in nutrient intake according to DDS quartiles, stratified by sex and age. Independently of age and sex, we observed that participants with the highest DDS (Q4) showed a lower number of nutrient inadequacies $(p<0.001)$. Also the prevalence of four or more inadequacies in nutrient intake decreased across DDS quartiles $(p<0.001)$ regardless of age or sex. When we used the EFSA dietary recommendations, we obtained similar results (Table S4.). 
Table 4. Number of inadequacies and distribution of participants with $\geq 4$ nutrients below $2 / 3$ of the dietary reference intake (DRI) according to DDS by age and sex.

\begin{tabular}{|c|c|c|c|c|c|}
\hline \multirow{4}{*}{$\begin{array}{l}\text { Inadequacies, mean } \pm \mathrm{SD} \\
\text { Participants, } n(\%)\end{array}$} & \multicolumn{5}{|c|}{ MEN: $\leq 70$ years } \\
\hline & Q1 $(n=787)$ & Q2 $(n=763)$ & $\mathrm{Q} 3(n=973)$ & Q4 $(n=489)$ & $p$ Value \\
\hline & $3.0 \pm 1.1$ & $2.3 \pm 1.1$ & $2.0 \pm 0.1$ & $1.7 \pm 0.7$ & $<0.001^{1}$ \\
\hline & $468(46.8)$ & $156(19.3)$ & $78(11.7)$ & $12(2.4)$ & $<0.001^{2}$ \\
\hline & \multicolumn{5}{|c|}{ WOMEN: $\leq 70$ years } \\
\hline & $\mathrm{Q1}(n=630)$ & Q2 $(n=610)$ & Q3 $(n=884)$ & $\mathrm{Q} 4(n=529)$ & $p$ Value \\
\hline Inadequacies, mean (SD) & $2.9 \pm 1.0$ & $2.5 \pm 1.1$ & $2.1 \pm 1.0$ & $1.7 \pm 0.8$ & $<0.001^{1}$ \\
\hline \multirow[t]{3}{*}{ Participants, $n(\%)$} & $169(38.2)$ & $145(23.8)$ & $81(11.0)$ & $23(2.7)$ & $<0.001^{2}$ \\
\hline & \multicolumn{5}{|c|}{ MEN: $>70$ years } \\
\hline & Q1 $(n=124)$ & Q2 $(n=136)$ & Q3 $(n=111)$ & $\mathrm{Q} 1(n=48)$ & $p$ Value \\
\hline Inadequacies, mean (SD) & $2.9 \pm 1.1$ & $2.6 \pm 1.2$ & $2.0 \pm 1.0$ & $1.6 \pm 0.9$ & $<0.001^{1}$ \\
\hline \multirow[t]{3}{*}{ Participants, n (\%) } & $51(44.0)$ & 37 (33.9) & $11(10.9)$ & $5(5.5)$ & $<0.001^{2}$ \\
\hline & \multicolumn{5}{|c|}{ WOMEN: $>70$ years } \\
\hline & Q1 $(n=138)$ & Q2 $(n=137)$ & Q1 $(n=177)$ & Q1 $(n=103)$ & $p$ Value \\
\hline Inadequacies, mean (SD) & $3.0 \pm 1.1$ & $2.5 \pm 1.1$ & $2.0 \pm 0.9$ & $1.7 \pm 0.8$ & $<0.001^{1}$ \\
\hline Participants, n (\%) & $38(42.7)$ & $30(24.6)$ & $14(9.8)$ & $6(3.0)$ & $<0.001^{2}$ \\
\hline
\end{tabular}

3.5. Multivariable Logistic Regression Model for Inadequate Intake of Four or More out Eight Micronutrients According to Food Group's Diversity Intake and Total DDS Quartiles

The risk of inadequate intake of four or more nutrients increased in the lower DDS quartiles, regardless of the model we chose to adjust by (Table 5). The adjusted odds ratio (OR) of inadequate intake was 28.56 (95\% CI 20.80-39.21) for Q1 compared to Q4. We analyzed the prevalence of inadequate intake according to the category of DD for each one of the included food groups and found the same trend for all of them except for the cereal food group. The groups showing the strongest association were vegetables and fruit. These results were comparable if the EFSA criteria were used to define inadequate intake (Table S5.). The adjustment by age as a quantitative variable did not change the results (data not shown).

Table 5. Multivariable logistic regression models for inadequate intake of four or more out eight micronutrients according to food group's diversity intake and total DDS quartiles in the PREDIMED-Plus study participants. Odds ratios ( $95 \%$ Confidence intervals).

\begin{tabular}{|c|c|c|c|c|}
\hline & $\begin{array}{c}\text { Q1 } \\
(n=1647)\end{array}$ & $\begin{array}{c}\mathrm{Q} 2 \\
(n=1647)\end{array}$ & $\begin{array}{c}\mathrm{Q3} \\
(n=1647)\end{array}$ & $\begin{array}{c}\mathrm{Q} 4 \\
(n=1646)\end{array}$ \\
\hline \multicolumn{5}{|c|}{ Total DDS } \\
\hline Model 1 & $27.42(20.13-37.34)$ & $10.00(7.30-13.72)$ & $4.37(3.14-6.09)$ & 1 (Ref.) \\
\hline \multirow[t]{2}{*}{ Model 2} & $28.56(20.80-39.21)$ & $9.97(7.25-13.70)$ & $4.33(3.11-6.04)$ & 1 (Ref.) \\
\hline & $\begin{array}{c}C 1 \\
(n=550)\end{array}$ & $\begin{array}{c}\mathrm{C} 2 \\
(n=1315)\end{array}$ & $\begin{array}{c}C 3 \\
(n=2482)\end{array}$ & $\begin{array}{c}C 4 \\
(n=2240)\end{array}$ \\
\hline \multicolumn{5}{|c|}{ Vegetable Group } \\
\hline Model 1 & $19.82(15.19-25.85)$ & 7.28 (5.85-9.10) & $2.74(2.22-3.38)$ & 1 (Ref.) \\
\hline Model 2 & $14.03(10.55-18.65)$ & $6.21(4.92-7.83)$ & $2.52(2.02-3.14)$ & 1 (Ref.) \\
\hline
\end{tabular}


Table 5. Cont.

\begin{tabular}{|c|c|c|c|c|}
\hline & $\begin{array}{c}C 1 \\
(n=845)\end{array}$ & $\begin{array}{c}\text { C2 } \\
(n=4497)\end{array}$ & $\begin{array}{c}\text { C3 } \\
(n=779)\end{array}$ & $\begin{array}{c}\text { C4 } \\
(\mathrm{v} 466)\end{array}$ \\
\hline \multicolumn{5}{|c|}{ Fruit Group } \\
\hline Model 1 & $19.75(11.87-32.86)$ & $3.76(2.30-6.15)$ & $2.23(1.29-3.84)$ & 1 (Ref.) \\
\hline \multirow[t]{2}{*}{ Model 2} & $11.62(6.81-19.81)$ & $2.71(1.62-4.53)$ & $2.02(1.15-3.57)$ & 1 (Ref.) \\
\hline & $\begin{array}{c}\text { C1 } \\
(n=350)\end{array}$ & $\begin{array}{c}C 2 \\
(n=4767)\end{array}$ & $\begin{array}{c}\text { C3 } \\
(n=1390)\end{array}$ & $\begin{array}{c}C 4 \\
(n=80)\end{array}$ \\
\hline \multicolumn{5}{|c|}{ Cereal Group } \\
\hline Model 1 & $1.33(0.54-3.31)$ & $1.13(0.47-2.71)$ & $0.90(0.37-2.19)$ & 1 (Ref.) \\
\hline \multirow[t]{2}{*}{ Model 2} & $0.83(0.32-2.19)$ & $0.84(0.33-2.14)$ & $0.71(0.28-1.82)$ & 1 (Ref.) \\
\hline & $\begin{array}{c}C 1 \\
(n=26)\end{array}$ & $\begin{array}{c}C 2 \\
(n=1254)\end{array}$ & $\begin{array}{c}\text { C3 } \\
(n=2770)\end{array}$ & $\begin{array}{c}C 4 \\
(n=2537)\end{array}$ \\
\hline \multicolumn{5}{|c|}{ Proteins group } \\
\hline Model 1 & $12.33(4.10-37.19)$ & $3.00(2.48-3.62)$ & $2.00(1.69-2.37)$ & 1 (Ref.) \\
\hline \multirow[t]{2}{*}{ Model 2} & $6.60(1.96-22.24)$ & $2.02(1.64-2.48)$ & $1.63(1.36-1.96)$ & 1 (Ref.) \\
\hline & $\begin{array}{c}C 1 \\
(n=686)\end{array}$ & $\begin{array}{c}\text { C2 } \\
(n=2447)\end{array}$ & $\begin{array}{c}C 3 \\
(n=2600)\end{array}$ & $\begin{array}{c}C 4 \\
(n=854)\end{array}$ \\
\hline \multicolumn{5}{|c|}{ Dairy Group } \\
\hline Model 1 & $9.51(6.88-13.14)$ & $3.35(2.50-4.49)$ & $1.52(1.12-2.06)$ & 1 (Ref.) \\
\hline Model 2 & $6.54(4.64-9.22)$ & $2.40(1.76-3.27)$ & $1.24(0.90-1.71)$ & 1 (Ref.) \\
\hline
\end{tabular}

Values are presented as OR and 95\% CI for inadequate intake of micronutrients as categorical variable according to total DDS and food's group diversity. Model 1: Adjusted for energy intake. Model 2: Adjusted for energy intake, sex, age, smoking habits, physical activity, educational level, MedDiet adherence, BMI, alcohol intake, living alone and civil status. Abbreviations: BMI, body mass index; C, category; DDS, dietary diversity score; Q, quartile.

\section{Discussion}

The present study, conducted among older individuals with MetS, showed that the greater the DDS the lower the risk of inadequate nutrient intake. Characteristics associated with a lower DDS are male sex, any marital status other than married, smoking habit and alcohol intake. Special attention should be paid to patients with these characteristics as they are likely to have a lower DDS.

It is known that demographic characteristics influence diet quality. The influence of age and sex on DDS could be attributable to multiple factors, including psychological and mental health issues, poorer nutritional knowledge, lack of cooking skills and increased loneliness [21,37]. Our results are in line with other studies regarding the impact of sex on the variety of food choices: Women consume more varied diets than men, presumably due to the traditional role as housewives and culinary knowledge [38]. Regarding age, despite other authors noting that dietary variety declined with age [39], we have not found the same trend, probably because the percentage of participants with $>70$ years old was small in our sample. Living alone has also been traditionally considered as a risk factor for poor dietary habits, mainly due to lower diversity of food intake [40,41]. We found lower DDS for widowed and divorced people, but not for people living alone.

In addition, some studies have highlighted that lower levels of education and economic status predict lower dietary variety $[42,43]$. Our results are not consistent on this point. According to socioeconomic level, the economic factors could explain low consumption of foods such as fish, fruits and vegetables, which require more frequent purchase and consumption and can also be more expensive. The discrepancy might be attributed to the fact that these studies have been carried out in non-European countries with heterogeneous socioeconomic levels. In our study, most participants had similar economic capacity (they were mostly retired) with the economic differences among them being small. Furthermore, the distribution of our population reflects the social and demographic characteristics of the Spanish population born in the 1940s-1960s. In that context, women had limited 
opportunity to pursue high levels of formal education. As the percentage of women is greater in the top quartile of DDS, this could be an attributable factor that explains that subjects with a higher DDS have a lower educational level.

In literature, smoking status and alcohol intake are the most important lifestyles variables related to food choices among older adults. In our study, non-smokers and drinkers of low quantities of alcohol showed higher DDS. Several studies have reported that smoking and drinking status are directly associated with less variety of food choices and poor nutrient intakes, consistent with our results $[44,45]$. However these findings have not been supported by a study carried out in middle-aged adults in Japan, probably because of socio-cultural differences and small sample size [46].

Dietary guidelines worldwide have promulgated the benefits of a variety of dietary intake, mainly because it is easier to provide the necessary amount of nutrients with a highly diverse diet. This could be especially important for obesity and chronic disease management $[47,48]$. In this regard, monotonous diets usually imply unhealthy eating habits, as well as the worsening in the progression of certain diseases, for example CVD [49]. In spite of this, some observational studies have related the diversity of food intake to higher rates of obesity and poor nutritional adequacy in adults $[13,16]$. However, in the case-control study of Karimbeiki et al. [16], cases were chosen from participants attending an obesity treatment group and dietary intake referred to the previous year, hence it is difficult to know whether it was cause or consequence. The study of Jayawardena et al. [13] estimate a DDS from a 24-h food record and not from a FFQ, and their results are not adjusted for total energy intake. Thus, their findings are not comparable to our results.

A recent non-systematic review concluded that "the scientific evidence to date does not support benefits of greater dietary diversity for optimal diet quality or healthy weight" [50] pointing out a need for standardized, reliable measures defining what diet diversity is. In the current study, high DDS level (Q4) was directly associated with adequate nutrient intake ( $\geq 4$ nutrients out of 8 ) even after adjustment for confounders such as sociodemographic and lifestyle variables. This association corroborates findings reported by other authors [17,51,52], emphasizing the need to increase diet variety, specifically in older adult populations, in order to achieve adequate nutrient intakes in these vulnerable groups. A variety of recommended foods, such as vegetables, fruit, cereals and dairy products, decreases the risk of inadequate nutrient intake, mainly because these foods group are rich in vitamins and minerals and other healthy nutrients such as dietary fiber [53].

Based on results obtained from the adjusted binary logistic regression analyses, the higher DDS of the majority of the food groups analyzed was inversely associated with the risk of inadequate intake of nutrients ( $\geq 4$ nutrients), except for cereals. Probably because the cereal group included not only whole grains, but also potatoes and refined grains. These findings are consistent with previous studies reporting a low probability of inadequate nutrient intakes in consumers of a high variety of foods groups, including vegetables and fruit [54], dairy products and protein-rich foods [51,55,56]. The notion is that for people who eat less variety of the healthy food groups, the intake of several nutrients might be endangered. For example, although vegetables provide a considerable amount of dietary fiber and water, green vegetables provide vitamins $B_{9}$, while yellow ones are rich in vitamin A and carotenes. Another example of variety within the same group is the protein group, which includes eggs, white meat, legumes, fish and nuts. This group is an excellent source of high-quality protein, minerals and vitamins. In particular, white meat is high in B-vitamins, while oily fish is rich in polyunsaturated fat and eggs provide vitamins $\mathrm{D}$ and $\mathrm{E}$ and minerals such as zinc, iron and iodine $[27,28]$.

Our study has some limitations. First, the study sample is not representative of the general population. Due to the trial inclusion and exclusion criteria, only older adults with MetS were included. Second, we did not have data about income status; however, we recorded the education level and employment status, which are both reasonable "proxy" indicators of socioeconomic status. Third, the cross-sectional design of the study does not allow for inferring causality. Irrespective of the direction of the associations, the variables included in the analysis have a high potential to improve the nutrient intake in older populations and allow the detection of groups of individuals more prone to nutrient 
deficiencies (those with lower DDS). Fourth, we used a FFQ to measure dietary intakes. Despite that the FFQ used has been validated in an adult Spanish population and has a good reproducibility and validity [26], it might not be the ideal tool to measure micronutrient intake [57]. For this reason, we considered that there was an inadequacy only when the intake did not reach $2 / 3$ of the DRIs, correcting the possible bias introduced by the FFQ and assuming in any case that the inadequate micronutrient intake would be higher than the estimated figures. Fifth, it is important to consider that, besides pharmacological treatments, chronic diseases entail changes in dietary habits and nutrient metabolism, which have not been assessed. Last, we have estimated a DDS following the methodology of Kant et al. [29]. However, we excluded non-recommended foods such as sweets, snacks, juices and sweet beverages and processed foods because these products are high-energy density foods, rich in sodium, sugar and saturated fat, and also low-nutrient density foods, thus we considered that the intake of these food groups could not increase dietary diversity [58]. A culinary fat group was also not taken into account because Spanish individuals consume olive oil almost exclusively [59].

Some strengths of our study are its large sample size $(n=6587)$ and the considerable amount of baseline information collected in a large ongoing primary prevention trial, using a standardized protocol that reduces information bias regarding reported food intakes, sociodemographic characteristics and lifestyles. The individual analysis of each food group's diversity can help to determine which aspects may maximize diet quality. The follow-up of this cohort will allow for the identification of any association between dietary diversity and clinical, metabolic and cardiovascular outcomes. Our results focus on the promotion of a healthy varied diet, specifically promoting the intake of a variety of vegetables and fruits among population groups with lower DDS such as men, smokers or widow(er)s people.

\section{Conclusions}

According to our findings, older Spanish adults with MetS had a high risk of inadequate nutrient intake. As DDS decreased, risk of inadequate nutrients intake increased. The impact of nutrient intake adequacy on the prevention of chronic non-communicable diseases, mainly among population groups with lower DDS such as men, older or widow people is very likely to play a crucial role from a public health perspective.

Supplementary Materials: The following are available online at http://www.mdpi.com/2072-6643/11/5/958/s1. Table S1: Percentage of participants of PREDIMED-Plus study with nutrient intake below $2 / 3$ of DRIs according to DDS, Table S2: Percentage of participants in the PREDIMED-Plus study with nutrient intake below $2 / 3$ of DRIs according to DDS, Table S3: Participants of PREDIMED-Plus study with nutrient intake below AR/AI proposed by EFSA according to DDS, Table S4: Number of inadequacies and distribution of participants with $\geq 4$ nutrients below EFSA criteria according to DDS stratified by sex, Table S5: Multivariable logistic regression models for inadequate intake of 4 or more out 8 micronutrients according to EFSA AR/AI by food group's diversity intake and total DDS quartiles in the PREDIMED-Plus study participants. Odds ratios (95\% Confidence intervals).

Author Contributions: N.C.-I., A.G., M.A.M.-G., J.S.-S., D.C., M.D.Z., J.V., F.A., J.W., J.A.M., L.S.-M., R.E., F.T., J.L., X.P., J.A.T., A.G.-R., M.D.-R., P.M., L.D., V.M., J.V., C.V., E.R., M.F. and M.R.-C. collected all the data from the PREDIMED-Plus trial. N.C.-I., A.G. and A.B.-C. designed the study; performed the analysis; and wrote the first draft of the manuscript. All authors contributed to the editing of the manuscript. All authors have read and approved the final version of the manuscript.

Funding: The PREDIMED-Plus trial was supported by the official funding agency for biomedical research of the Spanish government, ISCIII through the Fondo de Investigación para la Salud (FIS), which is co-funded by the European Regional Development Fund (three coordinated FIS projects led by J.S.-S. and J.V., including the following projects: PI13/00673, PI13/00492, PI13/00272, PI13/01123, PI13/00462, PI13/00233, PI13/02184, PI13/00728, PI13/01090, PI13/01056, PI14/01722, PI14/00636, PI14/00618, PI14/00696, PI14/01206, PI14/01919, PI14/00853, PI14/01374, PI16/00473, PI16/00662, PI16/01873, PI16/01094, PI16/00501, PI16/00533, PI16/00381, PI16/00366, PI16/01522, PI16/01120, PI17/00764, PI17/01183, PI17/00855, PI17/01347, PI17/00525, PI17/01827, PI17/00532, PI17/00215, PI17/01441, PI17/00508, PI17/01732, PI17/00926), the Especial Action Project entitled: Implementación y evaluación de una intervención intensiva sobre la actividad física Cohorte PREDIMED-Plus grant to J.S.-S., the European Research Council (Advanced Research Grant 2013-2018; 340918) grant to M.A.M.-G., the Recercaixa grant to J.S.-S. (2013ACUP00194), the grant from the Consejería de Salud de la Junta de Andalucía (PI0458/2013; PS0358/2016), the PROMETEO/2017/017 grant from the Generalitat Valenciana, the SEMERGEN grant and FEDER funds (CB06/03). None of the funding sources took part in the design, collection, analysis or interpretation of the 
data, or in the decision to submit the manuscript for publication. The corresponding author had full access to all the data in the study and had final responsibility to submit for publication.

Acknowledgments: The first author would like to acknowledge support by the Ministry of Education of Spain (FPU14/03630). The authors especially thank the PREDIMED-Plus participants for their collaboration and the PREDIMED-Plus staff for their support and effort. The authors also wish to thank Ingrid de Ruiter, MBChB, PhD, for English language support.

Conflicts of Interest: J.S.-S. reports serving on the board of and receiving grant support through his institution from International Nut and Dried Fruit Council; receiving consulting personal fees from Danone, Font Vella Lanjarón, Nuts for Life, and Eroski; and receiving grant support through his institution from Nut and Dried Fruit Foundation and Eroski. E.R., reports grants, non-financial support, and other fees from California Walnut Commission and Alexion; personal fees and non-financial support from Merck, Sharp \& Dohme; personal fees, non-financial support and other fees from Aegerion, and Ferrer International; grants and personal fees from Sanofi Aventis; grants from Amgen and Pfizer and; personal fees from Akcea, outside of the submitted work. X.P., reports serving on the board of and receiving consulting personal fees from Sanofi Aventis, Amgen, and Abbott laboratories; receiving lecture personal fees from Esteve, Lacer and Rubio laboratories. L.D. reports grants from Fundación Cerveza y Salud. All other authors declare no competing interests.

\section{References}

1. DeBoer, M.D.; Gurka, M.J.; Golden, S.H.; Musani, S.K.; Sims, M.; Vishnu, A.; Guo, Y.; Pearson, T.A. Independent associations between metabolic syndrome severity and future coronary heart disease by sex and race. J. Am. Cardiol. 2017, 69, 1204-1205. [CrossRef]

2. Micucci, C.; Valli, D.; Matacchione, G.; Catalano, A. Current perspectives between metabolic syndrome and cancer. Oncotarget 2016, 7, 38959-38972. [CrossRef]

3. Zhang, P.; Tian, B. Metabolic syndrome: An important risk factor for parkinson's disease. Oxid. Med. Cell. Longev. 2014, 2014, 729194. [CrossRef] [PubMed]

4. O'Neill, S.; O'Driscoll, L. Metabolic syndrome: A closer look at the growing epidemic and its associated pathologies. Obes. Rev. 2015, 16, 1-12. [CrossRef] [PubMed]

5. Guallar-Castillon, P.; Pérez, R.F.; García, E.L.; León-Muñoz, L.M.; Aguilera, M.T.; Graciani, A.; Gutiérrez-Fisac, J.L.; Banegas, J.R.; Rodríguez-Artalejo, F. Magnitude and management of metabolic syndrome in Spain in 2008-2010: The ENRICA Study. Rev. Española Cardiol. (Engl. Ed.) 2014, 67, 367-373. [CrossRef]

6. Boudreau, D.; Malone, D.; Raebel, M.; Fishman, P.; Nichols, G.; Feldstein, A.; Boscoe, A.; Ben-Joseph, R.; Magid, D.; Okamoto, L. Health care utilization and costs by metabolic syndrome risk factors. Metab. Syndr. Relat. Disord. 2009, 7, 305-314. [CrossRef] [PubMed]

7. De La Iglesia, R.; Loria-Kohen, V.; Zulet, M.A.; Martínez, J.A.; Reglero, G.; De Molina, A.R. Dietary strategies implicated in the prevention and treatment of metabolic syndrome. Int. J. Mol. Sci. 2016, 17, 1877. [CrossRef] [PubMed]

8. Calton, E.K.; James, A.P.; Pannu, P.K.; Soares, M.J. Certain dietary patterns are beneficial for the metabolic syndrome: Reviewing the evidence. Nutr. Res. 2014, 34, 559-568. [CrossRef] [PubMed]

9. Salas-Salvadó, J.; Guasch-Ferre, M.; Lee, C.-H.; Estruch, R.; Clish, C.B.; Ros, E. Protective effects of the mediterranean diet on type 2 diabetes and metabolic syndrome123. J. Nutr. 2016, 146, 920S-927S. [CrossRef] [PubMed]

10. Castro-Quezada, I.; Román-Viñas, B.; Serra-Majem, L. The mediterranean diet and nutritional adequacy: A review. Nutrients 2014, 6, 231-248. [CrossRef]

11. Martinez-Gonzalez, M.A.; Martín-Calvo, N. The major European dietary patterns and metabolic syndrome. Rev. Endocr. Metab. Disord. 2013, 14, 265-271. [CrossRef] [PubMed]

12. Aranceta Bartrina, J.; Arija Val, V.V.; Maíz Aldalur, E.; Martínez de Victoria Muñoz, E.; Ortega Anta, R.M.; Pérez-Rodrigo, C.; Quiles Izquierdo, J.; Rodríguez Martín, A.; Román Viñas, B.; Salvador Castell, G.; et al. Dietary guidelines for the Spanish population (SENC; diciembre 2016); the new graphic icon of healthy food. Nutr. Hosp. 2016, 33, 1-48. [CrossRef]

13. Jayawardena, R.; Byrne, N.M.; Soares, M.J.; Katulanda, P.; Yadav, B.; Hills, A.P. High dietary diversity is associated with obesity in Sri Lankan adults: An evaluation of three dietary scores. BMC Public Health 2013, 13, 314. [CrossRef]

14. Kennedy, E. Dietary diversity, diet quality, and body weight regulation. Nutr. Rev. 2004, 62, 78-81. [CrossRef] 
15. Tian, X.; Xu, X.; Zhang, K.; Wang, H. Gender difference of metabolic syndrome and its association with dietary diversity at different ages. Oncotarget 2017, 8, 73568-73578. [CrossRef]

16. Karimbeiki, R.; Pourmasoumi, M.; Feizi, A.; Abbasi, B.; Hadi, A.; Rafie, N.; Safavi, S. Higher dietary diversity score is associated with obesity: A case-control study. Public Health 2018, 157, 127-134. [CrossRef] [PubMed]

17. Murphy, S.P.; Wilkens, L.R.; Basiotis, P.P.; Foote, J.A.; Carlson, A. Dietary variety increases the probability of nutrient adequacy among adults. J. Nutr. 2004, 134, 1779-1785.

18. Azadbakht, L.; Mirmiran, P.; Esmaillzadeh, A.; Azizi, F. Dietary diversity score and cardiovascular risk factors in Tehranian adults. Public Health Nutr. 2006, 9, 728-736. [CrossRef]

19. Gholizadeh, F.; Moludi, J.; Yagin, N.L.; Alizadeh, M.; Nachvak, S.M.; Abdollahzad, H.; Mirzaei, K.; Mostafazadeh, M. The relation of Dietary diversity score and food insecurity to metabolic syndrome features and glucose level among pre-diabetes subjects. Prim. Care Diabetes 2018, 12, 338-344. [CrossRef] [PubMed]

20. Barba, L.R.; Cavelaars, A.; Veer, P.V.; Viñas, B.R.; Ngo, J.; Gurinovic, M.; Novakovic, R.; De Groot, L.C.; Matthys, C.; Majem, L.S. Projected Prevalence of Inadequate Nutrient Intakes in Europe. Ann. Nutr. Metab. 2011, 59, 84-95.

21. Dean, M.; Raats, M.M.; Grunert, K.G.; Lumbers, M. The Food in Later Life Team Factors influencing eating a varied diet in old age. Public Health Nutr. 2009, 12, 2421. [CrossRef]

22. Serra-Majem, L.; Bes-Rastrollo, M.; Román-Viñas, B.; Pfrimer, K.; Sánchez-Villegas, A.; Martinez-Gonzalez, M.A. Dietary patterns and nutritional adequacy in a Mediterranean country. Br. J. Nutr. 2009, 101, S21-S28. [CrossRef]

23. Buil-Cosiales, P.; Vioque, J.; Romaguera, D.; Martínez, J.A.; López-Miranda, J.; Bueno-Cavanillas, A.; A Tur, J.; Serra-Majem, L.; Martín, V.; Lapetra, J.; et al. Cohort Profile: Design and methods of the PREDIMED-Plus randomized trial. Int. J. Epidemiol. 2018, 48, 387-388.

24. Alberti, K.G.M.M.; Eckel, R.H.; Grundy, S.M.; Zimmet, P.Z.; Cleeman, J.I.; Donato, K.A.; Fruchart, J.C.; James, W.P.T.; Loria, C.M.; Smith, S.C. Harmonizing the metabolic syndrome: A joint interim statement of the international diabetes federation task force on epidemiology and prevention; national heart; lung; and blood institute; American heart association; world heart federation; International atherosclerosis society; and international association for the study of obesity. Circulation 2009, 16, 1640-1645. [CrossRef]

25. Willet, W. Nutritional Epidemiology, 3rd ed.; Oxford University Press: New York, NY, USA, 2013.

26. Martin-Moreno, J.M.; Boyle, P.; Gorgojo, L.; Maisonneuve, P.; Fernandez-Rodriguez, J.C.; Salvini, S.; Willett, W.C. Development and validation of a food frequency questionnaire in Spain. Int. J. Epidemiol. 1993, 22, 512-519. [CrossRef]

27. Moreiras, O.C.A.; Cabrera, L.; Cuadrado, C. Tablas de Composición de alimentos. (Spanish Food Composition Tables), 7th ed.; Pirámide: Madrid, Spain, 2003.

28. Mataix-Verdú, J.; García diz, L.; Mañas Almendros, M.; Emilio, M.d.V.; Llopis González, J. Tablas de Composición de Alimentos, 4th ed.; Universidad de Granada: Granada, Spain, 2009.

29. Kant, A.K.; Schatzkin, A.; Harris, T.B.; Ziegler, R.G.; Block, G. Dietary diversity and subsequent mortality in the First National Health and Nutrition Examination Survey Epidemiologic Follow-up Study. Am. J. Clin. Nutr. 1993, 57, 434-440. [CrossRef]

30. Farhangi, M.A.; Jahangiry, L. Dietary diversity score is associated with cardiovascular risk factors and serum adiponectin concentrations in patients with metabolic syndrome. BMC Cardiovasc. Disord. 2018, 18, 68. [CrossRef]

31. Schroder, H.; Fíto, M.; Estruch, R.; Martínez-González, M.A.; Corella, D.; Salas-Salvadó, J.; Lamuela-Raventos, R.M.; Ros, E.; Salaverría, I.; Fiol, M.; et al. A Short Screener Is Valid for Assessing Mediterranean Diet Adherence among Older Spanish Men and Women. J. Nutr. 2011, 141, 1140-1145. [CrossRef]

32. IOM Nutrient Recommendations: Dietary Reference Intakes. Available online: https://ods.od.nih.gov/ Health_Information/Dietary_Reference_Intakes.aspx (accessed on 4 May 2018).

33. Aranceta, J.; Serra-Majem, L.; Pérez-Rodrigo, C.; Llopis, J.; Mataix, J.; Ribas, L.; Tojo, R.; A Tur, J. Vitamins in Spanish food patterns: The eVe Study. Public Health Nutr. 2001, 4, 1317-1323. [CrossRef]

34. EFSA Dietary Reference Values and Dietary Guidelines. Available online: https://www.efsa.europa.eu/en/ topics/topic/dietary-reference-values (accessed on 1 October 2018).

35. Elosua, R.; García, M.; Aguilar, A.; Molina, L.; Covas, M.-I.; Marrugat, J. Validation of the Minnesota Leisure Time Physical Activity Questionnaire in Spanish Women. Med. Sci. Sports Exerc. 2000, 32, 1431-1437. [CrossRef] 
36. Elosua, R.; Marrugat, J.; Molina, L.; Pons, S.; Pujol, E. Validation of the Minnesota leisure time physical activity questionnaire in Spanish men. Am. J. Epidemiol. 1994, 139, 1197-1209. [CrossRef] [PubMed]

37. Larrieu, S.; Letenneur, L.; Berr, C.; Dartigues, J.F.; Ritchie, K.; Alperovitch, A.; Tavernier, B.; Barberger-Gateau, P. Sociodemographic differences in dietary habits in a population-based sample of elderly subjects: The 3C study. J. Nutr. Health Aging 2004, 8, 497-502.

38. Conklin, A.I.; Forouhi, N.G.; Surtees, P.; Wareham, N.J.; Monsivais, P. Gender and the double burden of economic and social disadvantages on healthy eating: Cross-sectional study of older adults in the EPIC-Norfolk cohort. BMC Public Health 2015, 15, 692. [CrossRef]

39. Westenhoefer, J. Age and gender dependent profile of food choice. Nutr. Oppor. Asia 2005, 57, 44-51.

40. Hanna, K.L.; Collins, P.F. Relationship between living alone and food and nutrient intake. Nutr. Rev. 2015, 73, 594-611. [CrossRef] [PubMed]

41. Vinther, J.L.; Conklin, A.I.; Wareham, N.J.; Monsivais, P. Marital transitions and associated changes in fruit and vegetable intake: Findings from the population-based prospective EPIC-Norfolk cohort; UK. Soc. Sci. Med. 2016, 157, 120-126. [CrossRef]

42. Ochieng, J.; Afari-Sefa, V.; Lukumay, P.J.; Dubois, T. Determinants of dietary diversity and the potential role of men in improving household nutrition in Tanzania. PLoS ONE 2017, 12, e0189022. [CrossRef]

43. Fukuda, Y.; Ishikawa, M.; Yokoyama, T.; Hayashi, T.; Nakaya, T.; Takemi, Y.; Kusama, K.; Yoshiike, N.; Nozue, M.; Yoshiba, K.; et al. Physical and social determinants of dietary variety among older adults living alone in Japan. Geriatr. Gerontol. Int. 2017, 17, 2232-2238. [CrossRef]

44. Hampl, J.S.; Ma, J.; Betts, N.M. Clustering of Lifestyle Behaviors: The Relationship between Cigarette Smoking, Alcohol Consumption, and Dietary Intake. Am. J. Health Promot. 2000, 15, 107-117. [CrossRef] [PubMed]

45. De Freitas, T.I.; Previdelli, Á.N.; Ferreira, M.P.N.; Marques, K.M.; Goulart, R.M.M.; de Aquino, R.C. Factors associated with diet quality of older adults. Rev. Nutr. 2017, 30, 297-306. [CrossRef]

46. Kobayashi, M.; Iwasaki, M.; Tsugane, S. Relationship between the variety of food consumed and sufficient nutrition in middle-Aged Japanese. Nutr. Food Sci. 2013, 43, 344-355. [CrossRef]

47. Vadiveloo, M.K.; Parekh, N. Dietary variety: An overlooked strategy for obesity and chronic disease control. Am. J. Prev. Med. 2015, 49, 974-979. [CrossRef] [PubMed]

48. Adebukola, C.O.; Ugwunna, U.M.; Ekerette, N.N. Dietary diversity and nutrient intake adequacy among women in Iwo Local Government Area; Osun State Nigeria. Afr. J. Food Agr. Nutr. Dev. 2017, 17, 12641-12656. [CrossRef]

49. Wirt, A.; E Collins, C. Diet quality-What is it and does it matter? Public Health Nutr. 2009, 12, 2473. [CrossRef]

50. De Oliveira Otto, M.C.; Anderson, C.A.M.; Dearborn, J.L.; Ferranti, E.P.; Mozaffarian, D.; Rao, G.; Wylie-Rosett, J.; Lichtenstein, A.H.; On behalf of the American Heart Association Behavioral Change for Improving Health Factors Committee of the Council on Lifestyle and Cardiometabolic Health and Council on Epidemiology and Prevention; Council on Cardiovascular and Stroke Nursing; et al. Dietary diversity: Implications for obesity prevention in adult populations: A science advisory from the American Heart Association. Circulation 2018, 138, e160-e168. [CrossRef] [PubMed]

51. Tavakoli, S.; Dorosty-Motlagh, A.R.; Hoshiar-Rad, A.; Eshraghian, M.R.; Sotoudeh, G.; Azadbakht, L.; Karimi, M.; Jalali-Farahani, S. Is dietary diversity a proxy measurement of nutrient adequacy in Iranian elderly women? Appetite 2016, 105, 468-476. [CrossRef] [PubMed]

52. Marshall, T.A.; Stumbo, P.J.; Warren, J.J.; Xie, X.J. Inadequate nutrient intakes are common and are associated with low diet variety in rural; community-dwelling elderly. J. Nutr. 2001, 131, 2192-2196. [CrossRef] [PubMed]

53. Masset, G.; Scarborough, P.; Rayner, M.; Mishra, G.; Brunner, E.J. Can nutrient profiling help to identify foods which diet variety should be encouraged? Results from the Whitehall II cohort. Br. J. Nutr. 2015, 113, 1800-1809. [CrossRef] [PubMed]

54. Meng, L.; Wang, Y.; Li, T.; Loo-Bouwman, C.A.V.; Zhang, Y.; Man-Yau Szeto, I. Dietary diversity and food variety in chinese children aged 3-17 years: Are they negatively associated with dietary micronutrient inadequacy? Nutrients 2018, 10, 1674. [CrossRef]

55. De Gavelle, E.; Huneau, J.F.; Mariotti, F. Patterns of protein food intake are associated with nutrient adequacy in the general french adult population. Nutrients 2018, 10, 226. [CrossRef] 
56. Azadbakht, L.; Mirmiran, P.; Azizi, F. Variety scores of food groups contribute to the specific nutrient adequacy in Tehranian men. Eur. J. Clin. Nutr. 2005, 59, 1233-1240. [CrossRef]

57. Ortiz-Andrellucchi, A.; Sánchez-Villegas, A.; Doreste-Alonso, J.; De Vries, J.; De Groot, L.; Serra-Majem, L. Dietary assessment methods for micronutrient intake in elderly people: A systematic review. Br. J. Nutr. 2009, 102, S118. [CrossRef] [PubMed]

58. Kant, A.K. Consumption of energy-dense, nutrient-poor foods by adult Americans: Nutritional and health implications. The third National Health and Nutrition Examination Survey, 1988-1994. Am. J. Clin. Nutr. 2000, 72, 929-936. [CrossRef] [PubMed]

59. Ruiz, E.; Ávila, J.M.; Valero, T.; Del Pozo, S.; Rodriguez, P.; Aranceta-Bartrina, J.; Gil, Á.; González-Gross, M.; Ortega, R.M.; Serra-Majem, L.; et al. Macronutrient Distribution and Dietary Sources in the Spanish Population: Findings from the ANIBES Study. Nutrients 2016, 8, 177. [CrossRef] [PubMed]

C 2019 by the authors. Licensee MDPI, Basel, Switzerland. This article is an open access article distributed under the terms and conditions of the Creative Commons Attribution (CC BY) license (http://creativecommons.org/licenses/by/4.0/). 